Психология. Журнал Высшей школы экономики,

2010. T. 7, № 3. С. 41-56.

\title{
ВОПРОСЫ ПСИХОЛОГИЧЕСКОЙ ТЕОРИИ СПОСОБНОСТЕЙ
}

\author{
В.Д. ШАДРИКОВ
}

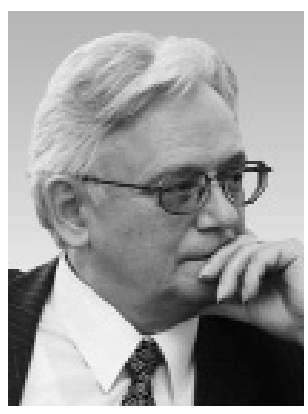

Шадриков Владимир Дмитриевич - научный руководитель факультета психологии ГУ-ВШЭ, академик РАО, доктор психологических наук, профессор.

Область научных интересов: психология деятельности и способности человека. Основные работы: «Проблемы системогенеза деятельности», «Происхождение человечности», «Мир внутренней жизни человека», «Способности человека».

Контакты: shadrikov@hse.ru, iso@hse.ru

\begin{abstract}
В настоящей работе представлена авторская теория способностей человека. Дается содержательное определение способностей, которые рассматриваются в трех измерениях: индивида, субъекта деятельности и личности. На основе предложенного понимания способностей предлагается решение актуальных вопросов: соотношения задатков и способностей, места способностей в структуре психики, взаимосвязи способностей и познавательных процессов.

Выходя за рамки познавательных способностей, автор предлагает общее понимание способностей, отнесенных к другим психологическим категориям.

В заключении предлагается система ментальных качеств человека.
\end{abstract}

Резюме

Ключевые слова: категории логики, способности, ментальные качества, познавательные процессы, духовные состояния, интеллектуализация способнос-

тей, психологическая функция, функииональная система способностей.

Несмотря на тысячелетнюю историю, вопросы психологической теории способностей являются актуальными и в настоящее время. Рассматривая состояние теоретического изучения способностей, С.Л. Рубинштейн сделал такой неутешительный вывод: «Прежде чем вводить понятие “способность” в систему психологической науки, необходимо очер-

Работа выполнена при поддержке программы «Научный фонд ГУ-ВШЭ», индивидуальный исследовательский проект № 10-01-0039 «Качество педагогического образования: проблемы и пути решения». 
тить его истинное содержание» (Рубинштейн, 1999, с. 535). И далее: «Термин “способности” в определениях, представленных в литературе, указывает только на то, что это нечто (способности) обусловливает успех в деятельности, но ничего не говорит нам о том, что есть это нечто» (Рубинштейн, 1960). Создание теории способностей предполагает, прежде всего, содержательное раскрытие понятия «способности», по словам С.Л. Рубинштейна, необходимо очертить истинное содержание понятия «способности».

Наиболее известная попытка дать определение, что такое способности, принадлежит Б.М. Теплову в статье «Способности и одаренность», написанной в 1961 г., практически одновременно с указанной работой С.Л. Рубинштейна (Рубинштейн, 1960). Хотя статья содержит всего 26 страниц, она стала хрестоматийной, разобранной на цитаты, вошедшие в различные учебники, статьи и монографии. На положениях этой статьи воспитано несколько поколений психологов. В силу значимости данной работы рассмотрим представленную в ней попытку определить, что такое способности.

«Три признака, - писал Б.М. Теплов, - всегда заключаются в понятии способности:

- во-первых, под способностями разумеются индивидуально-психологические особенности, отличающие одного человека от другого; никто не станет говорить о способностях там, где дело идет о свойствах, в отношении которых все люди равны...;

- во-вторых, способностями называют не всякие вообще индивидуаль- ные особенности, а лишь такие, которые имеют отношение к успешности выполнения какой-либо деятельности или многих деятельностей...;

- в-третьих, понятие способность не сводится к тем знаниям, навыкам и умениям, которые уже выработаны у данного человека» (Теплов, 1985, c. 16).

При ближайшем рассмотрении оказывается, что названные признаки не позволяют выделить способности из других психологических категорий, их нельзя считать отличительными характеристиками способностей. Способности здесь определяются как «особенности», но об особенностях можно говорить только тогда, когда определена вещь, у которой есть особенности. Особенности - это всегда особенности чего-то. Не определив вещь, нельзя говорить об особенностях.

По второму признаку можно заключить, что на успешность деятельности влияют не только способности, но, например, и мотивация, и переживания. Влияние на успешность деятельности является необходимым условием, но недостаточным.

Третий признак вообще не дает содержательной характеристики способностей, он только отграничивает их от других качеств, которые влияют на успешность деятельности, от знаний, навыков и умений.

Необходимо отметить, что сам Б.М. Теплов, анализируя проблему способностей и одаренности, писал: «Я не предлагаю дать общую теорию одаренности, не предполагаю даже развить какую-либо гипотезу о том, какова должна быть эта такая теория. В настоящее время это еще неисполнимо» (Теплов, 1985, с. 15). 
Следует отметить, что сложность определения способностей отмечали и западные ученые. Так, еще в 1923 г. Э. Клапаред, профессор Женевского университета, пробуя дать определение способностей, отмечал крайнюю трудность сделать это в общей форме. При этом он выделил три признака, которые содержит понятие «способности»: ния;

1) идею практического примене-

2) идею индивидуальной дифференциации (своеобразия);

3) идею природного предрасположения (он подчеркивал идею врожденности способностей) (Клапаред, 1927, с. 12-16).

Рамки статьи не позволяют подробно остановиться на истории проблем психологии способностей. Такой анализ проведен в наших работах (Шадриков, 2007, 2010).

Для определения понятия «способности» необходимо определить, к какой категории будет относиться это понятие.

Еще Аристотель выделял 10 основных категорий, под которые подпадало все, что подлежит осмыслению: субстанция, количество, качество, отношение, место, время, положение, обладание, действие, страдание. В качестве наиболее общих часто выделяют три категории: вещь, свойство (или качество) вещи, отношение одной вещи к другой. Следовательно, способность может рассматриваться или как вещь, или как свойство вещи, или как отношение одной вещи к другой.

Мы нередко сталкиваемся с выражениями типа: алмаз способен резать стекло; атом способен делиться; зеленый лист способен усваивать солнечную энергию; клетка способна переходить из состояния покоя в состояние активности; мозг способен отражать объективно существующий мир и т. д.

Из приведенных примеров явствует, что понятие «способности» относят не только к человеку, но и к любой вещи неорганического и органического мира, естественно или искусственно созданной, находящейся на разных ступенях эволюционного развития. Анализ использования понятия «способности» показывает, что оно применяется как категория свойства (качества) вещи.

Действительно, приведенные выражения можно перефразировать и сказать: клетка обладает свойством переходить из состояния покоя в состояние активности; мозг обладает свойством отражать объективно существующий мир; алмаз обладает свойством резать стекло и т. д.

Таким образом, понятие «способность» и понятие «свойство» (качество) в данном случае выступают как тождественные. Но всегда ли они тождественны? Очевидно, нет. Способности тождественны не любому свойству вещи, а такому, которое дает ее функциональную характеристику. Способности можно определить как свойство или совокупность свойств (качеств) вещи, системы, проявляющихся в процессе функционирования. Допустимо сказать, что это функциональные свойства вещи, обусловливающие эффективность реализации вещью некоторой функции. Способности (свойства вещи) проявляются во взаимодействии вещей, функционировании систем.

Способности как свойства объектов определяются структурой объектов 
и свойствами элементов этой структуры. По отношению к последним свойства объекта выступают как качества. Любое свойство проявляется в единстве качества и количества, имеет меру выраженности. Следовательно, способности также должны иметь меру выраженности.

В свете сказанного важно теперь определить, свойством какого объекта являются психологические способности.

Важнейшим вопросом здесь является установление взаимосвязи и отношений психологической функции, одаренности и способности; способностей и родовых форм деятельности; психических функций и функциональных систем, реализующих эти функции.

В рассматриваемом плане интересной представляется мысль С.Л. Рубинштейна о соотношении одаренности и психологической функции: «Одаренность неотождествляема с качеством одной функции - хотя бы даже и мышлением... Функции являются продуктом далеко идущего анализа, выделяющего отдельные психологические процессы, соотнесенные с предметами, их свойствами, отношениями, качествами, с их сущностью - вообще с миром, определенным в общих категориях диалектической логики. Одаренность так же, как и характер, определяет более синтетические, комплексные свойства личности. Она характеризует личность в соотношении с более конкретными условиями деятельности человека, которые сложились в результате исторического процесса, создавшего определенные формы разделения труда» (Рубинштейн, 1935, c. 480). Из приведенной цитаты мож- но сделать вывод о том, что психологическая функиия характеризуется аналитичностью и абстрактностью, отнесенностью к миру, определяемому в категориях диалектической логики; одаренность же, в противоположность психологической функции, характеризуется синтетичностью $u$ конкретностью, соотнесенностью с конкретными условиями деятельности.

Данная точка зрения представляется нам перспективной, но в ней недостает одного звена - способностей. И это не случайно. С.Л. Рубинштейн, анализируя данное понятие, выделяет общую и специальную одаренность и специальные способности: «Для одаренности существенное значение имеет соотношение с исторически сложившимися областями человеческой практики, человеческой культуры. В конечном счете специальная одаренность включает в себя соотношение внутренних психических условий с требованиями специальных видов деятельности. Это соотношение одаренности с конкретной деятельностью является не только абстрактным соотношением, а реальной связью, обусловливающей самое формирование одаренности. Специальные способности определяются в отношении к отдельным специальным областям деятельнос$m u$. Внутри тех или иных специальных способностей проявляется общая одаренность индивидуума, соотнесенная с более общими условиями ведущих форм человеческой деятельности» (Рубинштейн, 1935, с. 480).

Как видно из приведенной цитаты, С.Л. Рубинштейн фактически отождествляет специальные способности и специальную одаренность. 
Специальная же одаренность часто понимается им как одаренность (без дополнения «специальная»). Одаренность же всегда выступала как синтетическое понятие, совокупность внутренних данных или возможностей человека. Способности в их аналитической форме как отдельные качества при таком подходе из рассмотрения выпадают. Однако вернемся к приведенной выше цитате. С.Л. Рубинштейн отмечал, что «внутри тех или иных специальных способностей проявляется общая одаренность индивидуума». И это, несомненно, правильно, если рассматривать соотношение способностей и одаренности. Но в стороне осталось соотношение способности и психологической функции. Отмечается только, что одаренность не отождествима с качеством одной функции. Одаренность характеризуется синтетичностью, способность же характеризуется аналитичностью. Именно в конкретной деятельности способности реализуются отдельными психическими процессами, соотнесенными с конкретными предметами, их свойствами, отношениями, с их сущностью. Иными словами, способности являются конкретным проявлением психических функций.

И если мы видим, что у С.Л. Рубинштейна психологическая функция характеризуется аналитичностью и абстрактностью (отнесенностью с миром), то способность будет характеризоваться аналитичностью и конкретностью (отнесенностью к условиям конкретной деятельности).

Таким образом, психологическая функция характеризуется аналитичностью и абстрактностью, одаренность - синтетичностью $u$ конкретностью, способность - аналитичностью и конкретностью, которье выступают конкретным проявлением психологчческой функции.

В своем основном теоретическом исследовании «История развития высших психических функций» Л.С. Выготский сформулировал положения о том, что развитие высших психических функций идет через овладение субъектом собственными процессами поведения. И в этом плане, отмечал Л.С. Выготский, история развития психических функций еще не написана. «Невыясненность генезиса высших психических функций с неизбежностью приводит к метафизической по существу концепции: высшие и низшие формы памяти, внимания, мышления существуют рядом друг с другом, независимо одна от другой, они не связаны генетически, функционально или структурно, точно изначально сотворены в двойном виде» (Выготский, 1983, c. 14). «Наряду с механической памятью как высшая ее форма различается логическая память, над непроизвольным вниманием надстраивается произвольное, над воспроизводящим воображением возвышается творческое, над образным мышлением возносится, как второй этап, мышление в понятиях и т.д.» (там же, с. 13). К сожалению, подобная картина сохраняется во многом и сегодня.

И здесь мы вправе поставить вопрос: что же означает «овладеть психическими функциями?» Именно недостаточная теоретическая разработка данного вопроса приводит к задержкам и в практических работах. Но какое значение это имеет для проблемы способностей человека? 
Дело в том, что понятия «способности» и «психические функции» исследовались и исследуются раздельно, как две совершенно независимые линии. На самом же деле это два тесно связанных аспекта развития способностей. Развитие способностей идет на базе функциональных систем, реализующих отдельные психические функции, и одновременно как процесс развития культурнообусловленных операционных механизмов, овладевая которыми человек и овладевает своими способностями. В этом случае развитие способностей выступает как процесс биологического и культурного развития в их единстве.

Анализ работ по психологии способностей показывает наличие отрыва способностей от психических функций и перенос центра тяжести на их детерминацию со стороны деятельности. Стремление раскрыть культурную детерминацию способностей в противоположность их пониманию как внутренних скрытых свойств, качеств, сущностей приводит к разрьву природной и культурной составляющих способностей.

Психологический анализ показывает, что любую деятельность, осуществляемую в практической или идеальной форме, можно разложить на отдельные психические функции. В любой деятельности необходимо что-то воспринять, запомнить, представить, осмыслить, принять решение и т.д. Психические функции представляют собой наиболее общие родовые формы деятельности. Психофизиологические исследования убедительно показали, что отдельные психические функции реализуются сложными нейрофизиологи- ческими функциональными системами. Эти функциональные системы в структуре целостного мозга формировались для реализации определенных психических функций. Можно сказать, что функциональные системы обладают свойством, благодаря которому возможно осуществлять определенную психическую функцию. Это свойство функциональных систем и является общей природной способностью, отнесенной к конкретной психической функции.

Определив способности с позиции общего, мы можем рассмотреть их с позиции единичного и особенного. С позиции единичного, отдельного, индивидуального способности будут определяться тем, как общее свойство (конкретная способность воспринимать, запоминать и т.д.) выражено у конкретного индивида. Единичное будет представлено мерой выраженности свойства у конкретного индивида. Вполне естественно, что мера выраженности этого общего свойства у отдельных индивидов может быть различной. На этом этапе появляется проблема индивидуальных различий в способностях как различной меры выраженности общей способности.

И тогда мы можем дополнить данное выше определение и сказать, что способности есть свойства функциональных систем, реализуюших отдельные психические функиии, имеющие индивидуальную меру выраженности u проявляюшиеся в успешности $u$ качественном своеобразии освоения $и$ реализачии деятельности.

Изложенный выше подход раскрывает природу способностей, позволяет дать определение способностей индивида. Эти способности 
обеспечивали выживание индивида в природных условиях.

Дав определение способностей через свойства функциональных систем, мы ввели понятие «способности» в систему основных категорий психологии.

Ранее мы, опираясь на работы С.Л. Рубинштейна, отмечали, что психическую функцию можно рассматривать как родовую форму деятельности. Психологический анализ показывает, что любую деятельность, осуществляемую в практической или идеальной форме, можно разложить на отдельные психические функции. В любой деятельности необходимо что-то воспринять, запомнить, представить, осмыслить, принять решение и т. д. В этом случае реализация психических функций будет выступать как отдельнье психологические действия. Эти действия могут превращаться и в самостоятельные деятельности, когда ставится цель что-то воспринять (деятельность наблюдателя), запомнить, решить.

Адекватно описать психическую функцию как родовую форму психологического действия (деятельности) можно через психологическую функциональную систему деятельности.

Архитектоника этой системы в основных компонентах должна совпадать с архитектоникой функциональной системы трудовой деятельности, однако содержание каждого компонента будет специфичным для каждой способности так же, как и для каждой предметной деятельности. Специфическая особенность рассматриваемой системы состоит в том, что она обладает природным свойством, направленньм на реали- зацию определенной психической функции и проявляюшимся через функциональнье механизмы. Это свойство выступает в роли первичного средства, внутреннего условия, позволяющего достигнуть цели. В профессиональной деятельности в качестве таких средств, как известно, выступают знания, умения и способности субъекта деятельности.

Структура способностей в виде формальной схемы, отражающей представленные выше положения, изображена на рисунке 1. Эта схема, показывающая лишь принципиальные моменты архитектоники способностей, позволяет приблизиться к пониманию механизма опосредования внешних воздействий через внутренние условия, важнейшими из которых являются способности. Беря свое начало в функциональной системе трудовой деятельности, структура способностей, в свою очередь, помогает понять, как функционирует сама система деятельности.

Предложенное понимание структуры отдельных способностей позволяет нам выдвинуть гипотезу, основанную на том принципе, что эта структура едина для всех способностей и аналогична структуре деятельности. Фактически при множестве способностей реально существует единая структура деятельности, которая мультиплицируется в структуре отдельных способностей. Онтологически эта единая структура реализуется целостностью мозга как органа психики, функционально определяется целью деятельности и ее мотивацией.

Для полного понимания способностей как родовых форм деятельности необходимо, чтобы эта деятельность 


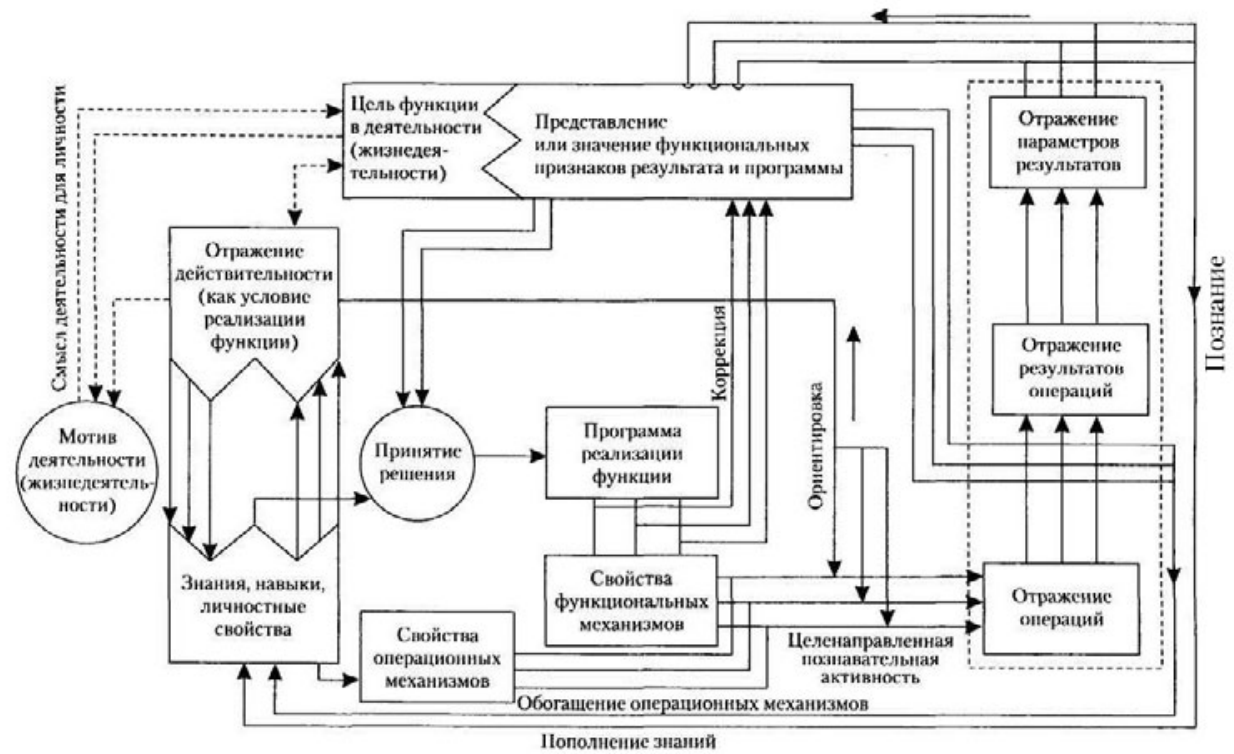

реализовывалась через систему действий - операций. В данном аспекте представляют интерес идеи Б.Г. Ананьева о комплексном изучении механизма психических функций. Согласно его схеме, развитие психических свойств проявляется как развитие функциональных, операционных, мотивационных механизмов. Функциональные механизмы на раннем этапе возникновения реализуют филогенетическую программу и складываются задолго до возникновения операционных механизмов. Между функциональными и операционными механизмами существуют сложные взаимодействия. Для развития операционных механизмов требуется определенный уровень функционального развития. В свою очередь, развитие операционных механизмов переводит в новую фазу развития и функциональные механизмы, их воз- можности прогрессивно возрастают, повышается уровень системности. В некоторые периоды индивидуального развития, к которым, как можно полагать, относятся школьный возраст, юность и зрелость человека, между операционными и функциональными механизмами устанавливаются соразмерность, относительное взаимодействие.

В концепции механизма психических функций, разработанной Б.Г. Ананьевым, сделана попытка решить проблему соотнесения биологических и социальных основ психической деятельности. Функциональные механизмы «детерминированы онтогенетической эволюцией и природной организацией человеческого индивида... Операционные механизмы не содержатся в самом мозге субстрате сознания, они усваиваются индивидом в процессе воспитания, 
образования, в обшей его социализации и носят конкретно-исторический характер» (Ананьев, 1977, с. 207). Функциональные механизмы относятся к характеристикам человека как индивида, операционные - как субъекта деятельности, мотивационные - как индивида и личности. Заметим, что идеи Б.Г. Ананьева о комплексном изучении механизма психических функций полностью исчерпываются представлением о функциональной системе способностей.

Исследования, проведенные под руководством автора, позволили выделить систему таких действий операций для восприятия, памяти и мышления, которые мы объединили в категорию интеллектуальных операций.

Способности, рассматриваемые с позиции конкретной деятельности, это способности субъекта, реализующего конкретную деятельность. Развитие способностей как способностей субъекта деятельности идет прежде всего за счет интеллектуализащии основных психических функций. Что стоит за этой фразой? Интеллектуализация способностей проявляется в вовлечении интеллектуальных операций в протекание основных психических функций: восприятие, память, воображение, представление. Однако там, где разворачивается интеллектуальная деятельность, обязательно начинают присутствовать процессы принятия решения (какие интеллектуальные операции и как использовать), программирования (как, в какой последовательности использовать выбранные операции), формирования различных критериев: какие операции предпочтительны (критерии предпочтительности), критерии достижения цели, критерии необходимости и достаточности выбранных операций, критерии эффективности полученных результатов.

Развитие способностей в направлении освоения интеллектуальных операций, формирования умственных навыков, включающих в себя операции программирования, принятия решений, использования различных критериев, будет характеризовать интеллектуализацию способностей.

В способностях субъекта деятельности человек выходит за рамки природных способностей.

Третьей линией развития способностей является постановка их под контроль нравственных качеств субъекта, под контроль совести.

Еще в Ветхом Завете мы находим свидетельства того, что человек изначально наделен способностями к познанию «добра» и «зла». Эти способности рассматриваются в качестве высшие способности человека как существа разумного. В Библии отмечается также, что эти способности могут быть развиты или остаться без развития.

Способности к познанию добра и зла есть способности личности. Как отмечал А. Бергсон, в предыстории человечества ум и мораль существовали в единстве, как единое целое (Бергсон, 1994, с. 44-45). Ум и мораль, содержащиеся друг в друге. И если углубиться в историю, то мы обнаружим мораль, более близкую к уму, и ум, более близкий к морали, чем у современного человека. Ум оформлял моральное требование. Мораль руководила сообществом 
людей и поведением индивида внутри сообщества. Постепенно это единство было разорвано. Наметились две линии развития: морали и ума. Но и сегодня действие ума опутано $и$ контролируемо моралью, а в морали проступают действия рассудка.

Мораль проявляется не только в конкретных решениях, но, что может быть более важно, определяет направление поиска, в том числе и в области науки и техники. Оба механизма (мораль и ум), которые вначале прослеживались друг в друге, должны были разойтись, чтобы вырасти. Но и сейчас в каждом из них представлен другой, имеется связь с другим.

Способности личности тесно связаны с переживаниями. Можно сказать, что это способности духовного состояния. Чем же характеризуется это духовное состояние? Оно характеризуется расширением сознания, активным включением в процесс постижения истины подсознания, установлением коммуникативной связи сознания и подсознания и тем самым резким расширением информационной базы понимания проблемы, энергетической активизацией, переключением эмоций с режима блокирования информации на режим энергетической подпитки.

Духовное состояние характеризуется гармонизацией личности, устранением противоречий с окружающей средой или блокированием этих противоречий, сосредоточением на познаваемой проблеме, на постижении истины, внутренним равновесием, позитивным взглядом на жизнь, высокой концентрацией устремлений, усилением воли и ее контроля со стороны личности, «Я».
Духовное состояние характеризуется переходом к образному мышлению, к продуктивному воображению, что, со своей стороны, способствует активизации информационного обмена с подсознанием, так как информация персонального подсознания хранится в образной и чувственной форме. Образность помогает осмыслить ситуацию целостно, раскрыть новые отношения, посмотреть на старые на новом уровне интеграции. В духовном состоянии слова и понятия могут переводиться в образы и чувства.

В способностях личности тесно сливаются способности индивида и его переживания, познание осуществляется за счет определенного духовного состояния.

Духовные ценности определяют конкретную точку зрения на вещь, выделяя ее качества, важные со стороны духовных ценностей. Духовный взгляд на мир обусловливает духовную картину мира. Мир предстается как мир взаимосвязанных ценностей, соотнесенный с духовными ценностями индивида. Если для рационального мышления важна утилитарная, практическая, объективная значимость, то для духовного важна этическая, нравственная значимость, определяемая в системе духовных координат личности.

Духовное состояние характеризуется чувством внутренней активности, единением духовных способностей и свойств, чувств и эмоций, единением умственных, нравственных, духовных качеств, стремлением к духовному прогрессу.

Обобщая сказанное, можно отметить, что решающим моментом в развитии способностей является их 
детерминированность индивидуальными ценностями. Именно индивидуальные ценности и будут определять качественную специфику способностей, от них будет зависеть, что увидит и запомнит человек, какая мысль у него появится, какова будет природа личностных сознаний.

Таким образом, подводя итог, можно утверждать, что содержательно определить способности возможно только рассматривая их в трех измерениях: индивида, субъекта деятельности и личности.

Способности человека как индивида отражают их природную (биологическую) сущность. Они сформировались для обеспечения выживания человека в естественных природных условиях. Способности индивида есть свойства его функциональных систем, реализующих отдельные психические познавательные и психомоторные функции, имеющие индивидуальную меру выраженности и проявляющиеся в успешности и качественном своеобразии познания окружающего предметного мира и организации адаптивного поведения (в том числе жизнедеятельности).

Способности человека как субъекта деятельности развиваются на базе природных способностей индивида. Под влиянием требований деятельности природные способности индивида приобретают черты оперативности, развиваются операционные механизмы, природные способности включаются в психологические функциональные системы, реализующие предметную и идеальную деятельность. Можно утверждать, что способности человека как субъекта деятельности есть свойства функциональных систем способностей, в струк- туре которых функционируют способности индивида (природные способности). Как и способности индивида, способности субъекта деятельности имеют индивидуальную меру выраженности и проявляются в успешности и качественном своеобразии освоения и реализации деятельности.

Способности субъекта деятельности есть проявление способностей индивида в конкретной деятельности, достроенные интеллектуальными операциями и в развитой форме реализуемые психологической функциональной системой, изоморфной психологической системе деятельности.

Ведущую роль в развитии способностей субъекта деятельности играют процессы:

- овладения субъектом своими способностями через овладение интеллектуальными операциями;

- тонкого приспособления способностей к условиям деятельности (придание им черт оперативности по Д.А. Ошанину).

Способности человека как личности представляет собой способности субъекта деятельности, поставленные под нравственный контроль личности. И если способности индивида сформировались в процессе филогенеза и обеспечивали, в первую очередь, выживание индивида в природе, способности субъекта деятельности, развиваясь на основе природных способностей, обеспечивают эффективное выполнение деятельности, то способности личности проявляются в поступках человека, обеспечивая социальное познание строго недетерминированного мира, так как люди, вступающие во взаимодействие, обладают свободой и волей. 
Приведенное выше понимание способностей дает возможность дать ответ на ряд актуальных вопросов.

\section{Задатки и способности}

Рассмотренное понимание способностей позволяет наметить пути решения проблемы соотношения задатков и способностей. Если функциональные системы, свойствами которых являются способности, представляют собой подсистемы единого целого - мозга, то в качестве элементов функциональных систем выступают отдельные нейроны и нейронные цепи (нейронные модули), которые в значительной мере специализированы в соответствии с назначением конкретной функциональной системы. Именно свойства нейронов и нейронных модулей целесообразно определить как специальные задатки. Вместе с тем, как показали исследования, активность, работоспособность, непроизвольная и произвольная регуляция, мнемические способности и т. д. зависят от свойств нервной системы, а вербальные и невербальные способности во многом определяются взаимодействием и специализацией полушарий головного мозга. Общие свойства нервной системы, специфику организации головного мозга, проявляющиеся в продуктивности психической деятельности, целесообразно отнести к общим задаткам.

При таком понимании способностей и задатков становится более ясным соотношение между ними. Способности не формируются из задатков. Способности и задатки являются свойствами: первые - свойствами функциональных систем, вторые - компонентов этих систем. Поэтому можно говорить только о развитии вещей, которым присущи данные свойства. С развитием системы изменяются и ее свойства, определяющиеся как элементами системы, так и их связями. Свойства функциональных систем (способности) - системные качества. При этом в свойствах системы могут проявляться и проявляются свойства элементов, ее составляющих (специальные задатки). Помимо этого, на продуктивность психической деятельности влияют свойства суб- и суперсистем, которые мы обозначили как общие задатки. Общие и специальные задатки, в свою очередь, также могут интерпретироваться как системные качества, если мы будем изучать элементы системы, свойствами которых они являются.

Существует и другое понимание задатков: их можно рассматривать в качестве генетических программ, определяющих развитие функциональных систем в структуре мозга и человека в целом как индивида. Рассматривая проблемы развития способностей, мы также не можем сказать, что способности формируются на основе задатков, ибо развиваться будут функциональные системы, а задатки вместе со средой будут управлять этим процессом. Данную точку зрения подтверждают многочисленные исследования близнецов. Так, например, в миннесотском исследовании самая высокая наследуемость обнаружена при измерении способностей и интеллекта (корреляция между членами близнецовых пар 0.6-0.7), следующая по величине наследуемость обнаруживается при измерении личностных показателей 
(около 0.5); наименьшая наблюдается в отношении религиозных и политических взглядов (Аткинсон и др., 2003).

По всей вероятности, соотношение задатков и способностей объясняется исходя из двух подходов, изложенных выше.

\section{Место способностей в структуре психики}

Понимание способностей как свойств функциональных систем, реализующих отдельные психические функции, позволяет указать место способностей в структуре психики. Как правило, при определении психики рассматриваются три ее аспекта: свойства высокоорганизованной материи мозга отражать объективный мир, субъективный образ объективного мира и переживания. Сравнивая определения психики и способностей, мы видим, что именно способности реализуют функцию отражения и преобразования действительности в практической и идеальной формах. Способности - одно из базовых качеств психики наряду с содержательной стороной, включающей знания об объективном мире и переживания. Способности конкретизируют общее свойство мозга отражать объективный мир, относя его к отдельным психическим функциям. Одновременно способности характеризуют индивидуальную меру выраженности этого свойства, отнесенного к конкретной психической функции. Таким образом, способности находят свое место в структуре психики, конкретизируя общее понятие психики как свойства мозга отражать объективный мир, дифференцируя это свойство на конкретные психические функции, внося в него меру индивидуальной выраженности, придавая ему деятельностный характер, ибо мера индивидуальной выраженности способности проявляется в успешности и качественном своеобразии освоения и реализации отдельных психических функций. Способности имеют сложную структуру, отражающую системную организацию мозга, межфункциональные связи и деятельностный характер психических функций.

\section{Общее понимание способностей}

Способности индивида, как отмечалось ранее, рассматриваются нами как свойства функциональных систем, реализующих отдельные психические функции, имеющие индивидуальную меру выраженности и проявляющиеся в успешности и качественном своеобразии освоения и реализации деятельности. В данном определении существенным является то, что способности являются свойством функциональных систем. Это определяющий, конституирующий фактор. Следовательно, мы можем ожидать, что в любом случае, где мы сталкиваемся с функциональной системой, реализующей те или иные психические функции, мы можем говорить о способностях.

Исходя из сказанного, мы можем заключить, что человек обладает не только познавательными способностями, но и способностями желать и переживать, так как и для мотивации, и для эмоций мы можем указать функциональные физиологические системы, которые их реализуют. 
Таким образом, мы видим, что познавательные способности есть только один из классов способностей. Расширение понятия «способности» на мотивацию и эмоции дает возможность более полно представить систему психических явлений и определить значение категории способностей в системе других психологических категорий. Это дает также возможность перенести на мотивацию и эмоции методы, наработанные при изучении познавательных способностей.

Общую схему взаимодействия психических функций, способностей и личностных качеств можно представить в виде рисунка 2. Функциональные физиологические системы являются генетически обусловленным базисом психической деятель- ности. Свойствами этих систем являются соответствующие способности: познавательные, мотивационные, эмоциональные. Устойчивые проявления соответствующих мотиваций, эмоциональных реакций становятся личностными качествами - чертами характера. По этому поводу С.Л. Рубинштейн писал, что «психические свойства - не изначальная данность; они формируются и развиваются в деятельности личности» (Рубинштейн, 1999, с. 513). Однако не все психическое содержание действия или поступка человека, не всякое психическое состояние может быть отнесено к свойствам личности. К ним могут быть отнесены только устойчивые мотивации и переживания. То, как формируются и закрепляются относительно устойчивые

Общая схема взаимодействий психических функций, способностей и личностных качеств

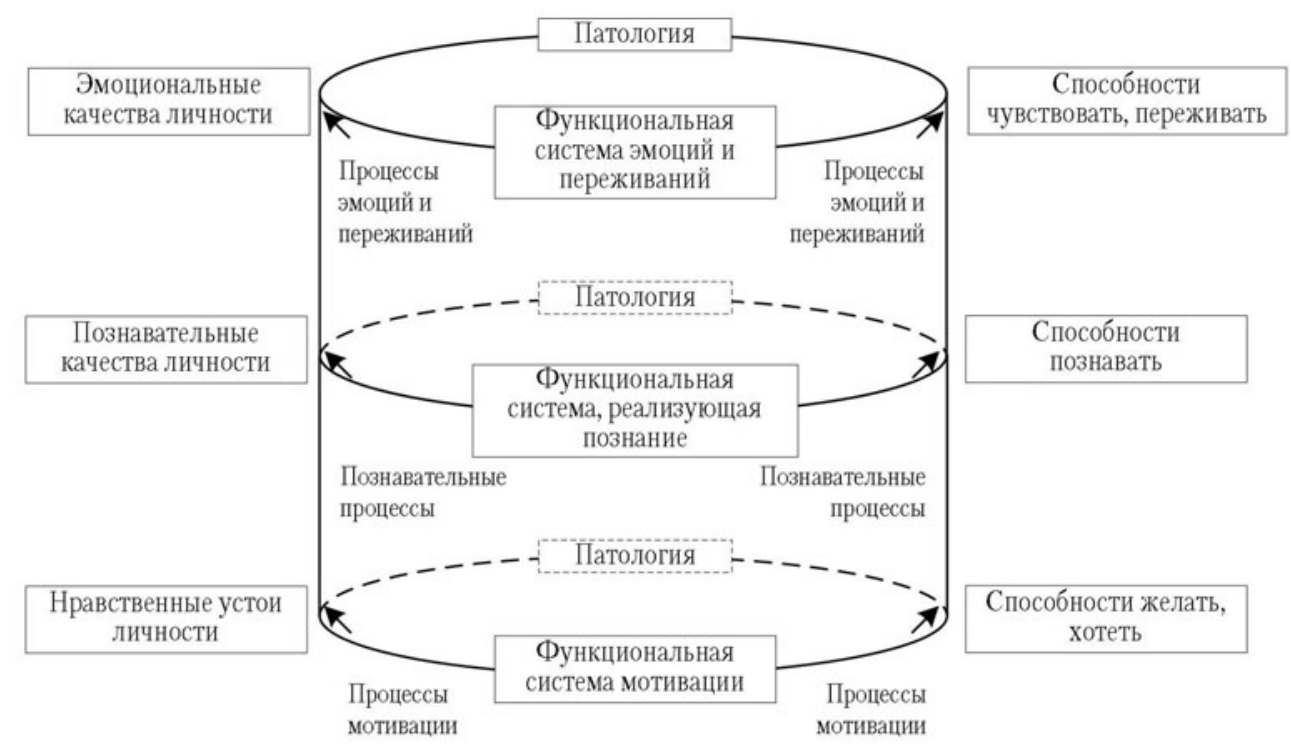


психические свойства личности, является вопросом, еще требующим своего решения.

Психические процессы и свойства личности неотделимы друг от друга, писал С.Л. Рубинштейн. Точно так же связаны между собой способности и психические свойства личности, ее характерологические свойства. Таким образом, мышление, мотивация и переживания тесно связаны друг с другом. «Мыслить, - отмечал С.Л. Рубинштейн, - человек начинает, когда у него проявляется потребность что-то понять... Поскольку мышление... исходит из потребностей и интересов человека, эмоциональные моменты чувства, выражающего в субъективной форме переживания, отношения человека к окружающему, включаются в каждый интеллектуальный процесс и своеобразие его ограничивают» (Рубинштейн, 1999, с. 317).

\section{Способности и познавательные процессы}

Определив способности как свойства функциональных систем, мы получили возможность связать способности с познавательными процессами, так как психические процессы относятся к тем же самым физиологическим системам и характеризуют процесс их функционирования. Ссылаясь на Л.М. Веккера (Веккер, 1974), отметим, что конечные характеристики психических процессов (процессов функционирования физиологических систем, реализующих отдельные психические функции) описываются в терминах свойств и отношений внешних объектов. Это описание позволяет перейти к харак- теристике продуктивности психических функций, к способностям субъекта деятельности. Таким образом, способности и познавательные процессы выступают как две стороны одного и того же объекта - функциональных физиологических систем, реализующих конкретные психические функции.

Обозначенный подход ликвидирует теоретический разрыв между способностями и психическими процессами, который представлен практически во всех учебниках психологии, как отечественных, так и зарубежных. Он позволяет дать классификацию способностей на основе традиционного разделения познавательных процессов и обогатить характеристики способностей свойствами и качествами результатов познавательных процессов.

\section{Система ментальных качеств человека}

Предлагаемая модель способностей человека одновременно выступает и как теоретический конструкт познания способностей, и как представление о развитии способностей.

Невозможно познать способности, ограничиваясь только одним аспектом: природным, деятельностным или социальным. Одаренность выступает как интегральное проявление способностей в целях конкретной деятельности. Здесь важно подчеркнуть принципиальное сходство общей архитектуры психологической системы деятельности и архитектуры психологической функциональной системы способностей. Их изоморфность раскрывает пути интеграции отдельных способностей в 
одаренность в структуре деятельности. В качестве системообразующих факторов одаренности выступают мотивы, цель и результат деятельности.

Интеллект можно определить как интегральное проявление способностей, знаний и умений. Уже в способностях присутствует элемент научения в виде формирующихся операционных механизмов, направленных на обработку материала. В интеллекте интеллектуальные операции дополняются более обобщенными операционными схемами, планами $и$ программами поведения, а также знаниями о внешнем предметном мире, о других людях и самом себе. Уро- вень интеллекта определяется уровнем развития отдельных способностей, наличием знаний, планов и программ использования интеллектуальных операций и их связями; иелостным характером функционирования интеллекта.

Талант есть проявление интеллекта в отношении конкретной деятельности, познания природы.

По совокупности изложенных выше результатов, по критериям, предъявляемым к психологическим теориям (Холл, Линдсей, 2000, с. 24), можно утверждать, что в данном случае мы имеем дело с психологической теорией способностей человека.

\section{Литература}

Ананьев Б.Г. О проблемах современного человекознания. М.: Наука, 1977.

Аткинсон Р.Л., Аткинсон Р.С., Смит Э.Е., Бем Д.Д., Нолен-Хоэксема С. Введение в психологию / Под ред. В.П. Зинченко, А.И. Назарова, Н.Ю. Спомиора. СПб.: Прайм-Еврознак, 2003.

Бергсон А. Два источника морали и религии. М.: Канон, 1994.

Веккер Л.М. Психические процессы. В 3 т. Л.: ЛГУ, 1974. Т. 1.

Выготский Л.С. Собрание сочинений: В 6 т. Т. 3: История развития высших психических функций. М.: Педагогика, 1983.

Клапаред Э. Как определить умственные способности школьника. Л.: Сеятель, 1927.
Рубинштейн С.Л. Основы психологии. М.: Государственное учебно-педагогическое издательство, 1935.

Рубинштейн С.Л. Проблемы способностей и вопросы психологической теории // Вопросы психологии. 1960. № 3.

Рубинштейн С.Л. Основы общей психологии. СПб.: Питер, 1999.

Теплов Б.М. Избранные труды: В 2 т. М.: Педагогика, 1985. Т. 1.

Холл К.Л., Линдсей Г. Теории личности. М.: Апрель-Пресс; Эксмо-Пресс, 2000.

Шадриков В.Д. Ментальное развитие человека. М.: Аспект-Пресс, 2007.

Шадриков В.Д. Профессиональные способности. М.: Университетская книга, 2010 . 